\title{
Market reactions to Australian boutique resource investor presentations
}

\author{
Andrew Ferguson* \\ Tom Scott \\ University of Technology, Sydney
}

\begin{abstract}
This paper examines the market reactions to 817 investor presentations by 326 Australian resource firms and finds evidence suggesting these events are informative. Furthermore, the positive returns do not reverse over the following 15 days, which contrasts with previous investor presentation research. However, consistent with the prior literature, extended long run cumulative abnormal returns are not significantly different from zero. This paper also documents stronger reactions to first time presenting firms, presentations that are announced to the market and firms exhibiting at the Africa Downunder and Excellence in Oil \& Gas conferences. There are also stronger reactions for firms with lower ownership concentration. Examining boutique resource firm investor presentations adds to the existing disclosure and dissemination literature due to the presence of relatively high information asymmetry in the extractive industries, a unique setting which contrasts with previous studies.
\end{abstract}

Keywords: Disclosure; Information asymmetry; Event study; Extractive industries; Dissemination

JEL classifications: G12; G14; M41

*Corresponding author: Professor Andrew Ferguson, School of Accounting, UTS, P.O. Box 123 Broadway NSW 2007, Australia.

Phone: +61 295143565

Fax: +61 295143669

Email address: Andrew.Ferguson@uts.edu.au 


\section{Introduction}

This study examines the abnormal market reaction to Australian boutique resource investor presentations to document whether they are significant events in terms of shareholder wealth effects. We provide evidence on whether presentations aid in capital allocation and are an effective use of investor and CEO time or are simply uninformative. We also investigate a range of resource presentation outlets, presentation initiation and firm level attributes to provide insight into which presentations are more highly valued, if any presentation outlet is better at picking future winners over the longer term and which firm specific characteristics influence the extent of the market reaction.

Although there has been a large range of literature on disclosure (for instance see Healy and Palepu, 2001) and dissemination (Ferguson and Crockett, 2003; Tetlock et al., 2008; Fang and Peress, 2009; Bushee et al., 2010; Soltes, 2010), firm presentations are an interesting and unique phenomenon to study as they occur in a physical location, with an opportunity for face-to-face interaction and questioning. Furthermore, presentations in the resource sector setting are generally not earnings focused and are often scheduled in advance with both the audience and presenter specifically attracted to the event. Therefore, the purpose of a presentation is often to build a broader understanding of firm operations and increase market participants’ firm specific awareness. However, as presenters must be invited and accept, there is potential for self-selection bias in the study of presentations as they are likely dominated by good news growth firms (Francis et al., 1997). Existing literature finds increases in analyst following and a positive market reaction to investor presentations, including stronger reactions to more important presentation outlets (Francis et al., 1997; Bushee et al., 2009). However, the positive reaction found to presentations to the New York Society of Security Analysts quickly reverses (Francis et al., 1997).

This paper adds to the literature by focusing on boutique conference presentations by Australian resource firms. Broadly, on the supply side, resource firms have incentives to publicize good news due to the inherently high information asymmetry environment. On the demand side, investors have incentives to attend and participate in resource industry investor presentations due to the potentially large payoffs. Resource disclosure is argued to contain difficult to interpret non-financial information, such as metal purity, drilling intercepts and geochemical composition (Ferguson and Crockett, 2003) which have greater relevance to resource firms than financial information (Ferguson et al., 2011a). This suggests a greater importance in attending presentations as these issues are discussed in detail. The Australian 
institutional setting is different from the U.S. and its less litigious nature suggests greater incentives to signal good news during investor presentations in a relatively costless manner. In addition, Australian continuous disclosure standards mean that if presentations contain significant new information they must be disclosed to the market as well, potentially creating a dual effect of both the resource presentation and wider market reactions to the presentation materials. There may also be a different type of investor attracted to smaller resource firms. Anecdotally for example, there may be the presence of 'gold bugs' or passionate gold investors and others motivated by the higher risk-return trade-off.

We investigate resource firm investor presentations at mining clubs and conferences by examining the abnormal market reaction to 817 presentations by 326 firms between 2000 and 2009. Specifically, we examine the reaction to presentations at the Diggers and Dealers, Association of Mining and Exploration Companies, Africa Downunder and both the Excellence in Mining and Exploration and Excellence in Oil and Gas conferences and the Sydney, Melbourne and Brisbane mining clubs. This paper documents significantly positive cumulative abnormal return (CAR) and abnormal turnover around presentations, indicative of presentations being significant market events. The significantly positive CAR in the 15 days leading up to the presentation suggests that there is either good news released before presentations or market anticipation of the presentation. In contrast with previous investor presentation research, there is no negative average returns or mean reversion over the following 15 days. However, the extended long run CAR is not significantly different from zero, suggesting that presentations have no consistent long term benefits or ability to select future winners. In a restricted sample, there are stronger reactions to first time presentations, presentations announced to the market and presentations at Africa Downunder and Excellence in Oil \& Gas, but only over the 31 day window. We also document a negative coefficient on ownership concentration, suggesting that presentations are of greater use to firms with more disperse ownership. Overall, the results show that resource firm investor presentations are significant events, but there is no consistent extended benefit.

The rest of this paper is structured as follows. Section 2 reviews related literature on investor presentations and develops the hypotheses. Section 3 outlines sample selection and the research model with results discussed in Section 4. The conclusions are presented in Section 5 . 


\section{Literature review and hypothesis development}

Recent research has studied publicizing or increasing awareness of firm news in an attempt to counteract the tendency to invest in the familiar (Huberman, 2001). Results show positive market reactions to behaviour that can raise awareness, such as the hiring of investor relation firms (Bushee and Miller, 2007; Solomon, 2009), being the focus of popular investment columns (Brown et al., 2009) and television interviews or recommendations (Busse and Green, 2002; Meschke and Kim, 2010). Press coverage also has a significant effect on price and information asymmetry (Ferguson and Crockett, 2003; Tetlock et al., 2008; Fang and Peress, 2009; Bushee et al., 2010; Soltes, 2010; Li et al., 2011). In addition, conference call communications between management and analysts are found to be significant market events (Tasker, 1998; Frankel et al., 1999), conference calls open to anyone produce different reactions to calls limited to invited participants (Bushee et al., 2003) and conference calls where all questions are not answered produce more negative returns (Hollander et al., 2010).

However, there is mixed evidence of whether the effect of firms publicizing their news is long lasting. The spin hypothesis proposes that when firms try to increase the dissemination of news, they are hyping good news which will lead to a temporary increase in price by non-information traders until the release of additional evidence that allows correct inferences to be drawn (Campbell et al., 1993). In contrast, the visibility hypothesis argues that a permanent increase in price will follow due to greater firm awareness, leading to higher analyst coverage, more diverse and geographically distant investors and improved liquidity (Merton, 1987). A long lasting effect could also be caused by a selection bias, in that good news firms are more likely to increase dissemination.

Investor presentations are very different to other dissemination mechanisms for a variety of reasons, including a physical location, face-to-face interaction with the potential for aggressive questioning, a non-earnings focus (especially in the case of resource firms), preadvanced scheduling and the selection of the presenting firm. Existing presentation research finds that presenters to the New York Society of Security Analysts, over 1986 to 1992, are typically larger and more profitable firms, consistent with their presentations being of interest to analysts (Francis et al., 1997). Furthermore, Francis et al. (1997) document a positive reaction that quickly reverses over the next 10 days and an increase in analyst following although there is no improvement in forecast accuracy. 
In recent years there has been dramatic growth in the number and variety of conference presentations, leading to Bushee et al. (2009) investigating 95,105 presentations at a wide range of outlets and locations. Bushee et al. (2009) document similar results to Francis et al. and stronger market reactions to larger, industry focused presentation outlets in money centres or holiday locations. A long lasting increase in analyst coverage and institutional shareholders is also documented post-presentation, with conference attributes moderating this relationship. For example, product focused conferences have a smaller effect on analyst coverage.

However, would current results be expected to extend to Australian resource firm investor presentations? The literature has largely ignored boutique industry presentations and any differential effect in relatively high information asymmetry settings, such as the Australian resource sector. The high prospective payoffs for mineral discovery and growth in resource delineation, coupled with the potentially different characteristics of small-cap resource firms presenting, could produce very different reactions from large American corporate presentations. Table 1 provides descriptive evidence of this difference by reporting the mean and median financial characteristics of all Australian Stock Exchange (ASX) firms in 2009 with Aspect Huntley data coverage by 2-digit Global Industry Classification Standard (GICS) groupings. Resource firms can fall into either energy or material categories depending on their operational focus and can be seen to be smaller, with less debt financing. However, resource firms have higher current ratios, likely reflecting the need to conserve cash for exploration and that bank loans are seldom offered to exploration firms. Furthermore, the lower profitability suggests that traditional cash flow analysis is less suited to many firms in the sector especially smaller mining development stage entities (DSE) who do not earn material cash flows. The different characteristics of resource firms to firms in other industries is supported by Ferguson et al. (2011b), who document that resource DSE have significant differences in firm characteristics, including lower debt, profitability and analyst coverage relative to similar sized non-resource firms. Overall, there is strong evidence that the resource sector has different firm characteristics leading to potentially higher information asymmetry and lower information intermediation.

A typical resource investor presentation does not have an earnings focus. Instead managers typically discuss the prospectivity of their tenements portfolios, key project progression and milestone accomplishment along the mine development life cycle. Ferguson et al. (2011a) documents that non-financial information is more relevant in predicting project 
failure for gold-developers, suggesting that the non-financial information disclosed in presentations is likely to be of greater relevance to resource sector investors. In addition, Australian continuous disclosure standards mean that if a presentation contains significant new information it must be disclosed to the market as well, potentially creating a dual effect that both the resource presentation attendees and wider market reacts to the presentation. An alternative view is that these resource presentations are routine events and contain noninformative 'spin' prompting no market reaction, particularly if the presentation only stresses known deposit characteristics and the presenter avoids answering audience questions. This leads to the first null hypothesis:

H1: There is no market reaction to resource firm investor presentations.

In addition, different presentation characteristics may affect the market reaction to the presentation. Specifically, different presentation outlets may prompt diverse market reactions based on the format and prestige of the event. The first presentation offered by a company may also prompt a stronger reaction as it could suggest an initiation of a broader dissemination policy or contain more price relevant information. There may be different reactions to firms focused on precious metals or Australian operationally focused firms. Therefore, the second null hypothesis is stated as:

H2: There is no association between presentation characteristics and the market reaction to resource firm investor presentations.

\section{Research model}

\subsection{Sample and data collection}

We manually construct the sample of resource firm investor presentations by contacting the organizers of resource conferences and mining clubs and asking for the date and name of presenting firms. We then manually check the information and remove presentations which are not made by ASX listed firms or are generic and non-firm focused in nature. ${ }^{1}$ We collect data from a large range of resource conferences and mining clubs, to allow the investigation of whether presentation attributes impact market reaction and to

\footnotetext{
${ }^{1}$ For example, if the presentation was titled "Thoughts on the mining tax" it was removed from the sample.
} 
ensure the robustness of inferences. However, a potential limitation is that as we capture a large range, but not all presentation outlets, presentation initiation could be misclassified or insignificant presentations excluded, biasing the results.

It is also important to recognise the difference between conferences and mining clubs. Resource conferences are annual events over several days, with multiple presentations a day and occasionally concurrent sessions. In contrast, mining clubs are monthly or bimonthly events with a comparatively longer presentation by generally one firm over lunch. Specifically, the sample includes Diggers and Dealers (DND), Association of Mining \& Exploration Companies (AMEC), Excellence in Mining \& Exploration (EME), Excellence in Oil \& Gas (EOG) and Africa Downunder ( $A D U)$ conferences and the Sydney $(S M C)$, Melbourne $(M M C)$ and Brisbane (BMC) mining club events (cumulatively the mining club events are labelled Club).

To conduct the analysis, we use market data from SIRCA daily data file, firm level financial data from Aspect Huntley, word count measures from ISYS and firms without data are removed from the sample. This results in a sample of 817 presentations however only 733 presentation observations have market data to calculate the longer return window of days -15 to 200. Furthermore, only 766 observations have readable data to calculate the ISYS measures of PREC and AUS, therefore the determinants regression is conducted on a sample of 766, 766 and 698 observations for the 31, 1 and 216 day windows, respectively.

\subsection{Return measurement}

The abnormal return for firm $i$ at event date $t$ is calculated as:

$$
A R_{i, t}=\left[\frac{P_{i, t}-P_{i, t-1}}{P_{i, t-1}}\right]-\left[\frac{R_{S r, t}-R_{S r, t-1}}{R_{S r, t-1}}\right]
$$

Where $A R_{i, t}$ is the abnormal return of firm $i$ at time $t, P_{i, t}$ is the share price of firm $i$ at time $t$ and $R_{s r, t}$ is the level of the Standard and Poors (S\&P) Small Resources Index at time $t$. Cumulative abnormal returns over the period $(p, q)$ are calculated as:

$$
\operatorname{CAR}_{i, t}(p, q)=\sum_{t=p}^{q} A R_{i, t}
$$

Abnormal turnover of shares at date $t$ for firm $i$ is calculated as: 
$\operatorname{ATURN}_{i, t}=\left[\frac{\text { VOL }_{i, t}}{\# \text { Shares }_{i, t}}\right]-\left[\frac{\text { EVOL }_{i, t}}{\# \text { Shares }_{i, t}}\right]$

Where $\operatorname{ATURN}_{i, t}$ is the abnormal turnover of firm $i$ at time $t, V O L_{i, t}$ is the volume of shares traded for firm $i$ at time $t$, \#Shares $s_{i, t}$ is the number of ordinary shares outstanding for firm $i$ at time $t$ and $E V O L_{i, t}$ is the average volume of shares traded for firm $i$ over days $t-90$ to $t-30 .^{2}$

\subsection{Regression model}

We use the following ordinary least squares (OLS) regression to provide evidence whether presentation and firm characteristics impact the significance of the resource presentation. To control for potential cross-sectional dependent variable correlation, we follow Gow et al. (2010) and cluster standard errors by year (also referred to as HumberWhite standard errors) to control for this problem. ${ }^{3}$ This approach allows for correlation within, but not across clusters and thus controls for the correlation of CAR between firms presenting at the same conference in the same year. CAR correlation could be caused by information transfer or a resource boom year.

$$
\begin{aligned}
& C A R_{i, t}=\beta_{0}+\beta_{1} D N D_{i, t}+\beta_{2} A M E C_{i, t}+\beta_{3} E M E_{i, t}+\beta_{4} E O G_{i, t}+\beta_{5} A D U_{i, t}+\beta_{6} I N T_{i, t}+ \\
& \beta_{7} A N N+\beta_{8} P R E C_{i, t}+\beta_{9} A U S_{i, t}+\beta_{10} P S D I S C_{i, t}+\beta_{11} S I Z E_{i, t}+\beta_{12} M O M_{i, t}+ \\
& \beta_{13} T O P 20_{i, t}+\varepsilon
\end{aligned}
$$

Where $C A R_{i, t}$ is the cumulative abnormal return of firm $i$ at time $t$ calculated per equations 1 and 2; $D N D_{i, t}$ is a binary variable equal to 1 for a Diggers and Dealers conference presentation and 0 otherwise; $A M E C_{i, t}$ is a binary variable equal to 1 for a Association of Mining \& Exploration Companies conference presentation and 0 otherwise; $E M E_{i, t}$ is a binary variable equal to 1 for an Excellence in Mining \& Exploration conference presentation and 0 otherwise; $E O G_{i, t}$ is a binary variable equal to 1 for a Excellence in Oil \& Gas conference presentation and 0 otherwise; $A D U_{i, t}$ is a binary variable equal to 1 for an

\footnotetext{
${ }^{2} 7$ observations did not have volume data over this period and the period $t+30$ to $t+90$ is substituted to calculate EVOL. Results are robust to the inclusion and exclusion of these observations.

${ }^{3}$ Alternate standard error specifications produce similar results.
} 
Africa Downunder conference presentation and 0 otherwise; $I N T_{i, t}$ is a binary variable equal to 1 if the presentation at time $t$ is the first presentation of firm $i$ and 0 otherwise; $A N N_{i, t}$ is a binary variable equal to 1 if the presentation at time $t$ by firm $i$ is announced to the market and 0 otherwise. ${ }^{4}$

$P R E C_{i, t}$ and $A U S_{i, t}$ proxy for firm focus on precious metals and Australian operations respectively. We follow Ferguson and Walker (2011) by using ISYS software to count specific word mentions in text documents when constructing these variables. Specifically, $P R E C_{i, t}$ is the count of the words 'gold', 'silver', 'palladium', 'platinum' and 'precious' over mentions of all minerals in the annual report of firm $i$ in year $t . A U S_{i, t}$ is the count of the word 'Australia' over mentions of all countries in the annual report of firm $i$ in year $t$. Variable construction naturally limits these variables to a range between 0 and 1. PSDISC is the number of price-sensitive announcements issued by firm $i$ over the 15 days before and after event date $t$, controlling for any other firm specific information released to the market.

$S I Z E_{i, t}$ is the natural logarithm of the market capitalization of firm $i$ as at the end of year $t$; $M O M_{i, t}$ proxies for resource sentiment as measured by the difference in S\&P Goldman Sachs Commodity Index (GSCI) spot price from the start of the presenting month to one year previously; TOP $20_{i, t}$ is the percentage of shares owned by the largest 20 shareholders as reported in the annual report of firm $i$ in year $t$ and $\varepsilon_{i}$ is the normally distributed error term.

\section{Results}

\subsection{Descriptive statistics}

Table 2 presents counts for each conference and club presentation outlet and presentation characteristics over time, with the final sample comprising of 817 presentations by 326 firms. The sample is skewed towards the later part of the decade, with two conferences, EME and EOG starting in 2008. There are considerably more conference presentations than mining club presentations, consistent with resource conferences having many presenting firms in one day. Presentation initiation is stable until a large jump during the resource boom year of 2008, with a corresponding increase in presentation outlets. Firms increasingly announce investor presentations to the market over the time period examined, consistent with a greater emphasis on disseminating firm news.

\footnotetext{
${ }^{4}$ We include in this measure market announcements that direct investors to the presentation (for example, on the firm website) and presentation announcements from other outlets over the 15 days before and after event date $t$, due to the likely identical nature of the presentations.
} 
Descriptive statistics for presenting firms are contained in Table 3. There is a large range in the descriptive statistics, including substantial differences between means and medians, likely due to the sample including both large firms and a significant number of DSE's. Indicative of the sample containing equity funded explorers, we note that several firms have few liabilities. There is also a large range in market capitalization, with the smallest firm being worth less than $\$ 1$ million, although the median is $\$ 129$ million. The mean percentage of shares owned by the top 20 shareholders is $61.38 \%$ (median $61.31 \%$ ). PREC and AUS have similar descriptive statistics with means of 0.420 and 0.431 , respectively. Both ISYS variables have the lowest and highest possible minimum and maximum of 0 and 1, respectively. On average firms release 4.83 (median 4.00) pricesensitive disclosures in the 31 day window around the investor presentation (i.e., -15 to 15 ).

Table 4 illustrates differences between firm characteristics for presenting firms split by club (Club) and conference (Conference) presentations, although many firms present at both conferences and clubs. These results indicate that firms presenting at mining clubs are significantly bigger and less focused on Australian operations than firms presenting at conferences. This is likely due to conferences giving a large number of local explorers' shorter time slots in DSE focused investment sections. In contrast, as mining clubs are limited to one speaker over lunch, organisers may have incentives to attract better known firms or firms with novel or controversial development concepts. Interestingly, there is no significant difference in the number of price-sensitive disclosures or precious metal focus by club and conference firms.

\subsection{Market reaction}

Fig. 1 graphically illustrates an upward, positive CAR around the 15 days before and after the presentation. There is also a distinct rise on the presentation day $(t=0)$. In addition, the steeper slopes pre-rather than post-presentation, suggest a positive market build up due to anticipation of good news in the presentation. ${ }^{5}$ Fig. 2 shows a spike in abnormal daily turnover centred on event day 0.

\footnotetext{
${ }^{5}$ The identity of presenting firms is likely known before the presentation date however we are unable to identify when the market becomes aware of this information. We acknowledge that any potential signalling or selection effect may be impounded at this unobservable date rather than the presentation date. Therefore, the market reaction to the presentation is most likely a reaction to information content than selection or signalling effects, biasing against the likelihood of finding a significant market reaction. This approach is consistent with prior presentation research (Francis et al., 1997; Bushee et al., 2009). We also recognize the distance between when the market is aware of the upcoming presentation likely varies across presentation outlets as does the magnitude of the selection or signalling effect.
} 
Daily abnormal returns and turnover over event days -15 to 15 are reported in Table 5 , depicting a significant positive return on event day 0 of $0.59 \%$. There are also sporadic significant positive abnormal returns in the pre- and post-periods which, along with the lack of consistent negative returns, suggest that the positive reaction to the presentation is not quickly reversed. Furthermore, there is significant positive daily abnormal turnover on days 3 to 1 . Together these results show that resource firm investor presentations are meaningful and informative events. There is another cluster of significant positive abnormal turnovers around day 8, although we cannot suggest a cause.

Table 6 reports $t$-tests on whether CAR windows are significantly different from 0 , with the -15 to 15 day window reporting a CAR of $4.8 \%$. Importantly, all CAR windows over the presentation are significantly positively different from 0 , indicating a positive market reaction to resource firm investor presentations. The significant abnormal return on event day 0 provides confidence that the longer CAR window results are not driven by correlation of returns, which would likely be worse over longer windows. The pre-presentation windows are consistently significant and larger than the post-presentation CAR windows, mirroring the graphical representation. Again, this result suggests that the market reacts positively in the lead up to the presentation. The security return results of Tables 5 and 6 both suggest that the positive reaction to presentations is not quickly reversed due to either presentations being uninformative events or mean reversion. This result contrasts with previous research (Francis et al., 1997), likely due to the comparatively higher information asymmetry and the lower information intermediation present in the resource sector relative to settings in prior literature. We also examine whether there is any long term market benefit over days -15 to 200. However, due to data restrictions this is run on a restricted sample of 733 presentations. Although there is a slightly positive CAR, it is not significantly different from 0 . This result suggests that presentations do not have long term price benefits due to greater firm awareness or that presentation outlets cannot pick future winners. Overall, this evidence suggests that resource firm investor presentations are informative events in an equity markets context.

\subsection{Market reaction determinants}

Table 7 reports results of OLS regressions of CAR on presentation and firm attributes. ${ }^{6}$ The results show there is a stronger reaction for first time presenting firms over the 31 and 216 day windows. This suggests the greater value of disseminating firm news

\footnotetext{
${ }^{6}$ Variance Inflation Factor's are all lower than 2.5, suggesting no problematic multicollinearity (Lardaro, 1993).
} 
when the firm is a relative unknown. Presentations at the Excellence in Oil \& Gas and Africa Downunder conferences also had stronger reactions over the -15 to 15 day window. However, these results do not extend to the 1 or 216 day windows, indicating that no presentation outlet provides a markedly superior disclosure platform or credibility. As the result is found only in the 31 day window, it could suggest that $A D U$ and EOG firms either release good news before the presentation or the market anticipates more of the gains. Alternatively, the positive coefficient is consistent with EOG or $A D U$ having a selection effect or that they are intrinsically better at selecting winners over a 31 day window. We interpret the significant negative coefficient on $D N D$ on the presentation date as a function of the pre-release of detailed Diggers and Dealers programmes removing any signalling effect. Presentations that are announced to the market also have a stronger 1 day reaction consistent with greater investor access to firm news and price-sensitive information being announced per ASX guidance.

There is some evidence $(p<0.1)$ that precious metal focused firms have stronger market reactions, potentially indicative of active 'gold bugs' however this result does not extend to the longer windows. There is no evidence that Australian focused firms have different market reactions. Unsurprisingly, a greater amount of firm specific news over the 31 day window is also associated with a higher market return over the same length window. Firms with greater ownership concentration have more negative reactions, consistent with large shareholders typically being value investors rather than active traders. This result also suggests that presentations are an effective communication method for firms with a disperse ownership base. We note the flipping sign for the commodity price index (MOM) depicts the importance of commodity prices in predicting future returns of resource stocks, relative to a short term window where firm specific information appears to be more important.

\subsection{Robustness and sensitivity testing}

In unreported results, we test the robustness of the main findings by using alternate benchmarks. We use the ASX 300 Materials and ASX 300 Metals and Mining Indexes to calculate abnormal returns. Application of alternative benchmarks produce similar results. To test the sensitivity of the market reaction determinants, the regression is re-run with alternate variable measurement. First, based on judgement from reading firm descriptions in the annual report, we create binary variables equal to one if the firm is focused on precious metals or Australian operations. This allows us to re-run the determinants regression using the full 
samples of 817, 817 and 733 for the 31, 0 and 216 day windows, respectively. This specification produces very similar results to those reported, providing confidence that the exclusions did not bias results. Second, resource momentum is recalculated as the six month change in the resource commodity price and the commodity price level at the time of the presentation. This produces similar results apart from $A D U$ no longer being significantly associated to the 31 day CAR window. Third, to control for any time effect we add a binary variable equal to one if the presentation was held after 2006, which produces similar results. ${ }^{7}$ Fourth, we run the determinants regression for the 31 and 1 day windows using only observations which also have data for the 216 day window. This specification produces similar results, providing confidence that there is no data restriction effect. Fifth, the outlying $1 \%$ and $5 \%$ of CAR observations are removed to test for any outlier effect. The results are consistent apart from $A D U$ and PREC are not significantly associated to the 31 and 1 day CAR windows, respectively. However, this difference is consistent with the highest positive reactions being to Africa Downunder and precious metal focused firms which would be removed from this analysis.

A potential methodological issue with conducting event studies in the small-cap resource sector is non-synchronous or thin trading biasing results (Brown and Warner, 1985; Kallunki, 1997; Leemakdej, 2009). To provide confidence that non-synchronous trading does drive or bias the main results we pro-rate allocate daily returns to any immediately preceding non-trading days, which produces consistent, although slightly weaker results (Kallunki, 1997). ${ }^{8}$ Second, we remove the 362 observations where the stock does not trade in any of the 15 days before or after the investor presentation. ${ }^{9}$ The resulting sub-sample produces similar, but stronger results. Fourth, as non-parametric rank tests can provide superior insight in samples prone to non-synchronous trading (Leemakdej, 2009), we compare whether there is a difference between the abnormal return on event day 0 relative to the 15 days before and after using the non-parametric Mann-Whitney U test and find significantly higher returns on event day 0 (z-score $=2.575)$. This result also holds in the sub-sample of firms that trade

\footnotetext{
${ }^{7}$ We split on 2006 due to the increasing number of resource firm investor presentations after 2007, coupled with a resource 'boom'. Alternate year controls produce similar results.

${ }^{8}$ Kallunki (1997) also proposes using the closing bid price however given the high information asymmetry present in the sample this would likely introduce more noise and thus we do not use this method.

${ }^{9}$ These non-trading days could be caused by non-synchronous trading, trading halts or database errors. In particular, there is a database error in the 7 event days around the 25th of August 2009 which effects 42 observations. Main results and robustness tests are robust to both the inclusion and exclusion of these 42 observations.
} 
continuously. Overall, we conclude that non-synchronous trading does not appear to be biasing the results and that the main findings of this paper are robust.

\section{Conclusions}

This paper adds to the literature by documenting that resource firm investor presentations are informative events and aid in capital allocation. The positive returns leading up to the presentation date suggests they follow good news stories or are partly anticipated by the market. Furthermore, the positive returns do not reverse over the following 15 days in contrast with previous literature, although there is no significant long term positive return. We provide further insight by investigating the effect of presentation and firm attributes on the market reaction. These results suggest a superior CAR by first time presenting firms, presentations announced to the market and presentations at Africa Downunder and Excellence in Oil \& Gas conferences. There are also stronger returns to firms with lower ownership concentration.

These results add to the disclosure and dissemination literature by examining boutique industry presentations in the unique setting of the Australian resource sector with its relatively high information asymmetry and important non-financial disclosures. Furthermore, the results are of practical interest to both resource firms and investors in the mining industry.

\section{Acknowledgements}

The assistance of resource conferences and mining clubs in creating a list of resource firm investor presentations was appreciated. We wish to especially thank Lyn Collins (Melbourne Mining Club), Suzanne Christie (Diggers \& Dealers), Tammy Caldwell (Paydirt Media), Brad Court (Resourceful Events), Denyse McClements (AMEC) and Taryn Rodier and Chris Sabin (Sydney Mining Club). The research assistance of Alexey Feigin and Andrew Walker is acknowledged along with comments and suggestions from Matthew Grosse, Stephen Kean and Gabriel Pundrich. Finally, Trevor Sykes, patron of the Sydney Mining Club is thanked for his support. 


\section{References}

Brown, P., Ferguson, A. and Jackson, A., 2009. Pierpont and the capital market. Abacus 45, 147-170.

Brown, S. and Warner, J., 1985. Using daily stock returns: The case of event studies. Journal of Financial Economics 14, 3-31.

Busse, J. and Green, C., 2002. Market efficiency in real time. Journal of Financial Economics 65, 415-437.

Bushee, B., Matsumoto, D. and Miller, G., 2003. Open versus closed conference calls: the determinants and effects of broadening access to disclosure. Journal of Accounting and Economics 34, 149-180.

Bushee, B. and Miller, G., 2007. Investor Relations, Firm Visibility, and Investor Following. Available at SSRN: http://ssrn.com/abstract $=643223$

Bushee, B., Jung, M. and Miller, G., 2009. Conference Presentations and the Disclosure Milieu, Available at SSRN: http://ssrn.com/abstract=1480448

Bushee, B. Core, J. Guay, W. and Hamm, S., 2010. The Role of the Business Press as an Information Intermediary. Journal of Accounting Research 48, 1-18.

Campbell, J., Grossman, S. and Wang, J., 1993. Trading volume and serial correlation in stock returns. Quarterly Journal of Economics 108, 905-940.

Fang, L. and Peress. J., 2009. Media Coverage and the Cross-Section of Stock Returns. Journal of Finance 64, 2023-2052.

Ferguson, A. and Crockett, A., 2003. Information transfer and press coverage: The case of the Gawler Craton gold boom. Pacific-Basin Finance Journal 11, 101-120.

Ferguson, A., Clinch, G. and Kean, S., 2011a. Predicting the Failure of Developmental Gold Mining Projects. Australian Accounting Review 56, 44-53.

Ferguson, A., Grosse, M., Kean, S. and Scott, T., 2011b. Your Governance or Mine? Australian Accounting Review, Forthcoming.

Ferguson, A. and Walker, A., 2011. Restoration and rehabilitation provisions in the materials and energy sector. Working paper, University of Technology, Sydney.

Francis, J., Hanna J., and Philbrick, D., 1997. Management Communications with Securities Analysts. Journal of Accounting and Economics 24, 363-94.

Frankel, R., Johnson, M. and Skinner, D., 1999. An Empirical Examination of Conference Calls as a Voluntary Disclosure Medium. Journal of Accounting Research 37, 133150.

Gow, I., Ormazabal, G. and Taylor D., 2010. Correcting for Cross-Sectional and Time-Series Dependence in Accounting Research. The Accounting Review 85, 483-512.

Healy, P. and Palepu, K., 2001. Information asymmetry, corporate disclosure, and the capital markets: A review of the empirical disclosure literature. Journal of Accounting Economics 31, 405-440.

Hollander, S., Pronk, M. and Roelofsen, E., 2010. Does Silence Speak? An Empirical Analysis of Disclosure Choices during Conference Calls. Journal of Accounting Research 48, 531-563.

Huberman, G., 2001. Familiarity Breeds Investment. The Review of Financial Studies 14, 659-680.

Kallunki, J., 1997. Handling missing prices in a thinly traded stock market: implications for the specification of event study methods. European Journal of Operational Research 103, 186-197.

Lardaro, L., 1993. Applied Econometrics. Harper Collins, New York.

Leemakdej, A., 2009. Detecting Abnormal Return of Infrequently Traded Stock in Event Study. Available at SSRN: http://ssrn.com/abstract=1436090 
Li, E., Ramesh, K. and Shen, M., 2011. The Role of Newswires in Screening and Disseminating Value-Relevant Information in Periodic SEC Reports. The Accounting Review 86, 669-701.

Merton, R., 1987. A simple model of capital market equilibrium with incomplete information. Journal of Finance 42, 483-510.

Meschke, J. and Kim, A., 2010. CEO Interviews on CNBC. Available at SSRN: http://ssrn.com/abstract=1627683

Solomon, D., 2009. Selective Publicity and Stock Prices. University of Southern California Working Paper, Available at SSRN: http://ssrn.com/abstract=1540309

Soltes, E., 2010. News Dissemination and the Impact of the Business Press. Working paper, Harvard University.

Tasker, S., 1998. Bridging the information gap: Quarterly conference calls as a medium of voluntary disclosure. Review of Accounting Studies 3, 137-167.

Tetlock P., Saar-Tsechansky, M. and Macskassy, S., 2008. More Than Words: Quantifying Language to Measure Firms’ Fundamentals. The Journal of Finance 63, 1437-1467. 
Table 1

Descriptive statistics for ASX firms by Industry in 2009

\begin{tabular}{|c|c|c|c|c|c|c|c|c|c|c|c|}
\hline Variables & & Energy & Mat. & $\begin{array}{c}20 \\
\text { Indust. }\end{array}$ & $\begin{array}{c}25 \\
\text { Cons. } \\
\text { Disc. } \\
\end{array}$ & $\begin{array}{c}30 \\
\text { Con. } \\
\text { Staple } \\
\end{array}$ & $\begin{array}{c}35 \\
\text { Health- } \\
\text { care } \\
\end{array}$ & Fin. & I.T. & Telecom. & Util. \\
\hline \multirow{2}{*}{ Total Assets } & Mean & 453.1 & 617.4 & 807.5 & 870.1 & $2,463.3$ & 228.2 & $11,236.9$ & 77.7 & $2,994.8$ & $2,256.4$ \\
\hline & Median & 20.4 & 11.7 & 101.3 & 60.0 & 98.7 & 13.2 & 158.0 & 22.5 & 26.2 & 357.9 \\
\hline \multirow{2}{*}{ Total Liabilities } & Mean & 182.6 & 295.1 & 494.1 & 448.1 & $1,350.0$ & 98.3 & $10,139.2$ & 42.5 & $1,627.5$ & $1,590.5$ \\
\hline & Median & 1.8 & 0.7 & 49.4 & 27.5 & 48.7 & 2.6 & 45.2 & 5.8 & 8.3 & 220.1 \\
\hline \multirow{2}{*}{ Current Ratio } & Mean & 11.07 & 56.70 & 2.23 & 3.03 & 2.49 & 6.90 & 15.07 & 4.10 & 1.62 & 4.82 \\
\hline & Median & 4.95 & 5.13 & 1.38 & 1.41 & 1.38 & 2.57 & 1.61 & 1.30 & 0.84 & 1.81 \\
\hline \multirow{2}{*}{ Debt-to-Equity } & Mean & $29 \%$ & $32 \%$ & $38 \%$ & $34 \%$ & $35 \%$ & $30 \%$ & $47 \%$ & $35 \%$ & $35 \%$ & $41 \%$ \\
\hline & Median & $8 \%$ & $6 \%$ & $33 \%$ & $31 \%$ & $33 \%$ & $17 \%$ & $22 \%$ & $20 \%$ & $24 \%$ & $38 \%$ \\
\hline \multirow{2}{*}{$R O A$} & Mean & $-69 \%$ & $-60 \%$ & $-17 \%$ & $-11 \%$ & $-17 \%$ & $-59 \%$ & $-16 \%$ & $-128 \%$ & $-28 \%$ & $-13 \%$ \\
\hline & Median & $-15 \%$ & $-16 \%$ & $5 \%$ & $5 \%$ & $1 \%$ & $-24 \%$ & $2 \%$ & $4 \%$ & $7 \%$ & $1 \%$ \\
\hline \multirow{2}{*}{ Total Revenue } & Mean & 292.9 & 363.3 & 629.5 & 626.8 & $3,447.7$ & 180.7 & 88.4 & 75.9 & $1,771.2$ & 474.4 \\
\hline & Median & 0.5 & 0.1 & 116.4 & 69.6 & 92.1 & 2.5 & 0.0 & 15.8 & 38.1 & 28.5 \\
\hline \multirow{2}{*}{ Operating Exp. } & Mean & -246.8 & -280.9 & -551.5 & -528.9 & $-3,181.7$ & -154.9 & -77.0 & -63.7 & $-1,077.3$ & -384.8 \\
\hline & Median & -6.0 & -3.0 & -95.0 & -61.2 & -85.1 & -8.7 & 0.0 & -14.4 & -23.3 & -12.2 \\
\hline \multirow{2}{*}{ Net CFO } & Mean & 37.6 & 68.8 & 53.5 & 55.6 & 198.4 & 18.2 & 171.9 & 9.4 & 556.7 & 81.2 \\
\hline & Median & -0.8 & -0.7 & 7.6 & 2.1 & 0.5 & -1.0 & 3.4 & 1.0 & 1.5 & 6.5 \\
\hline \multirow{2}{*}{ Constituents } & Count & 209 & 625 & 185 & 154 & 43 & 148 & 280 & 98 & 27 & 32 \\
\hline & $\%$ & $12 \%$ & $35 \%$ & $10 \%$ & $9 \%$ & $2 \%$ & $8 \%$ & $16 \%$ & $5 \%$ & $1 \%$ & $2 \%$ \\
\hline
\end{tabular}

Table 1 presents means and medians for selected financial characteristics by industry category, as defined by two-digit GICS codes as at the end of 2009. Industry categories are Energy, Materials, Industrials, Consumer Discretionary, Consumer Staples, Healthcare, Financials, Information Technology, Telecommunications and Utilities, respectively. Total Assets, Total Liabilities, Total Revenue, Operating Exp. and Net CFO are in millions of Australian dollars and are the figures reported in the Aspect Huntley database for 2009. I also report the industry breakdown by percentage of ASX constituents as at the end of 2009. 


\section{Table 2}

Summary statistics for resource firm investor presentations

\begin{tabular}{|c|c|c|c|c|c|c|c|c|c|c|c|}
\hline & 2000 & 2001 & 2002 & 2003 & 2004 & 2005 & 2006 & 2007 & 2008 & 2009 & Total \\
\hline \multicolumn{12}{|c|}{ Presentation outlets } \\
\hline$D N D$ & 25 & 26 & 29 & 30 & 32 & 34 & 33 & 35 & 32 & 30 & 306 \\
\hline$E M E$ & 0 & 0 & 0 & 0 & 0 & 0 & 0 & 0 & 45 & 34 & 79 \\
\hline$E O G$ & 0 & 0 & 0 & 0 & 0 & 0 & 0 & 0 & 27 & 23 & 50 \\
\hline$A D U$ & 0 & 0 & 0 & 7 & 14 & 17 & 17 & 21 & 28 & 42 & 146 \\
\hline$S M C$ & 0 & 3 & 12 & 9 & 6 & 14 & 11 & 10 & 13 & 16 & 94 \\
\hline$M M C$ & 0 & 2 & 3 & 2 & 6 & 3 & 2 & 6 & 4 & 2 & 30 \\
\hline$B M C$ & 0 & 0 & 0 & 0 & 0 & 4 & 3 & 2 & 2 & 1 & 12 \\
\hline Club & 0 & 5 & 15 & 11 & 12 & 21 & 16 & 18 & 19 & 19 & 136 \\
\hline Total & 25 & 31 & 44 & 48 & 58 & 91 & 80 & 98 & 176 & 166 & 817 \\
\hline
\end{tabular}

\begin{tabular}{|c|c|c|c|c|c|c|c|c|c|c|c|}
\hline \multicolumn{12}{|c|}{ Presentation characteristics } \\
\hline INT & 25 & 15 & 18 & 18 & 24 & 33 & 18 & 39 & 82 & 54 & 326 \\
\hline$A N N$ & 3 & 4 & 11 & 16 & 22 & 50 & 40 & 64 & 118 & 113 & 441 \\
\hline
\end{tabular}

Table 2 presents counts for presentation characteristics. DND is the Diggers and Dealers conference, AMEC is the Association of Mining \& Exploration Companies conference, EME and EOG are the Excellence in Mining \& Exploration and Oil \& Gas conferences, respectively and $A D U$ is the Africa Downunder conference. $S M C, M M C$ and $B M C$ stand for the Sydney, Melbourne and Brisbane mining club presentations, respectively, and Club is presentations at any of the three mining clubs (SMC, MMC or BMC). INT is a binary variable equal to 1 for the first firm presentation. ANN is a binary variable equal to 1 if the presentation is announced to the market. 


\section{Table 3}

Descriptive statistics for presenting firms

\begin{tabular}{lrrrrrr}
\hline Continuous variables & \multicolumn{1}{c}{ Mean } & \multicolumn{1}{c}{ Median } & \multicolumn{1}{c}{ Min. } & \multicolumn{1}{c}{ Max } & Std. dev. & $\boldsymbol{N}$ \\
\hline Current Assets & 366,241 & 20,784 & 113 & $27,712,596$ & $2,008,217$ & 817 \\
Total Assets & $1,567,250$ & 62,209 & 696 & $129,353,349$ & $8,774,599$ & 817 \\
Total Liabilities & 844,852 & 12,747 & 14 & $96,932,737$ & $5,517,314$ & 817 \\
Net CFO & 205,181 & -833 & $-2,141,185$ & $23,247,474$ & $1,544,164$ & 817 \\
MCAP & $1,502,685$ & 117,691 & 529 & $144,714,234$ & $8,027,384$ & 817 \\
SIZE & 16.394 & 16.281 & 10.877 & 23.395 & 2.029 & 817 \\
TOP20 & 62.19 & 61.96 & 14.51 & 99.48 & 17.27 & 817 \\
MOM & 1.49 & 31.39 & -286.29 & 214.56 & 114.07 & 817 \\
PSDISC & 4.83 & 4.00 & 0.00 & 30.00 & 4.24 & 817 \\
& & & & & & \\
\hline Restricted sample & & & & & & \\
PREC & 0.420 & 0.323 & 0.000 & 1.000 & 0.341 & 766 \\
AUS & 0.431 & 0.378 & 0.000 & 1.000 & 0.265 & 766
\end{tabular}

Table 3 presents descriptive statistics for presenting firms. Current Assets, Total Assets, Total Liabilities and Net CFO are in thousands of Australian dollars and are the figures reported in the annual report of firm $i$ in year $t . M C A P$ is the market capitalization in thousands of Australian dollars of firm $i$ at the end of year $t$, as measured by shares outstanding times closing share price. SIZE is the natural logarithm of MCAP. TOP20 is the pert Previor 


\section{Table 4}

Univariate analysis on presenting firm characteristics

\begin{tabular}{|c|c|c|c|c|c|}
\hline Variable & Club & Conference & $t$-stat & & $n$ \\
\hline Current Assets & $1,192,544$ & 201,223 & 2.879 & $* *$ & 817 \\
\hline Total Assets & $5,234,945$ & 834,789 & 2.828 & $* *$ & 817 \\
\hline Total Liabilities & $3,069,745$ & 400,527 & 2.547 & $*$ & 817 \\
\hline Net CFO & 759,808 & 94,419 & 2.655 & $* *$ & 817 \\
\hline MCAP & $4,478,701$ & 908,356 & 3.294 & $* * *$ & 817 \\
\hline SIZE & 17.712 & 16.130 & 7.490 & $* * *$ & 817 \\
\hline TOP20 & 67.398 & 61.147 & 3.856 & $* * *$ & 817 \\
\hline PSDISC & 5.103 & 4.781 & 0.698 & & 817 \\
\hline \multicolumn{6}{|c|}{ Restricted sample } \\
\hline PREC & 0.387 & 0.423 & -1.072 & & 766 \\
\hline AUS & 0.377 & 0.445 & -2.867 & $* *$ & 766 \\
\hline
\end{tabular}

Table 4 presents univariate analysis of presenting firm characteristics split by whether the presentation was at a mining club or conference. Club is equal to 1 if the presentation was at $S M C$, $M M C$ or $B M C$ and Conference is equal to 1 if the presentation was at DND, AMEC, EME, EOG or ADU. Current Assets, Total Assets, Total Liabilities and Net CFO are in thousands of Australian dollars and are the figures reported in the annual report of firm $i$ in year $t$. MCAP is the market capitalization in thousands of Australian dollars of firm $i$ at the end of year $t$, as measured by shares outstanding times closing share price. SIZE is the natural logarithm of MCAP. TOP20 is the percentage of shares owned by the largest 20 shareholders, as reported in the annual report of firm $i$ in year $t$. PSDISC is the number of price-sensitive announcements issued by firm $i$ over the 15 days before and after event date $t$. PREC is the count of the words 'gold', 'silver', 'palladium', 'platinum' and 'precious' over mentions of all minerals in the annual report of firm $i$ in year $t$. AUS is the

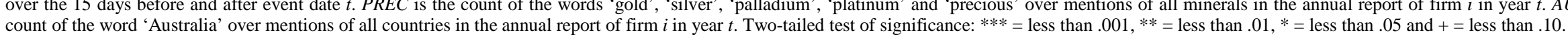




\section{Figure 1}

Cumulative abnormal returns over event days -15 to 15

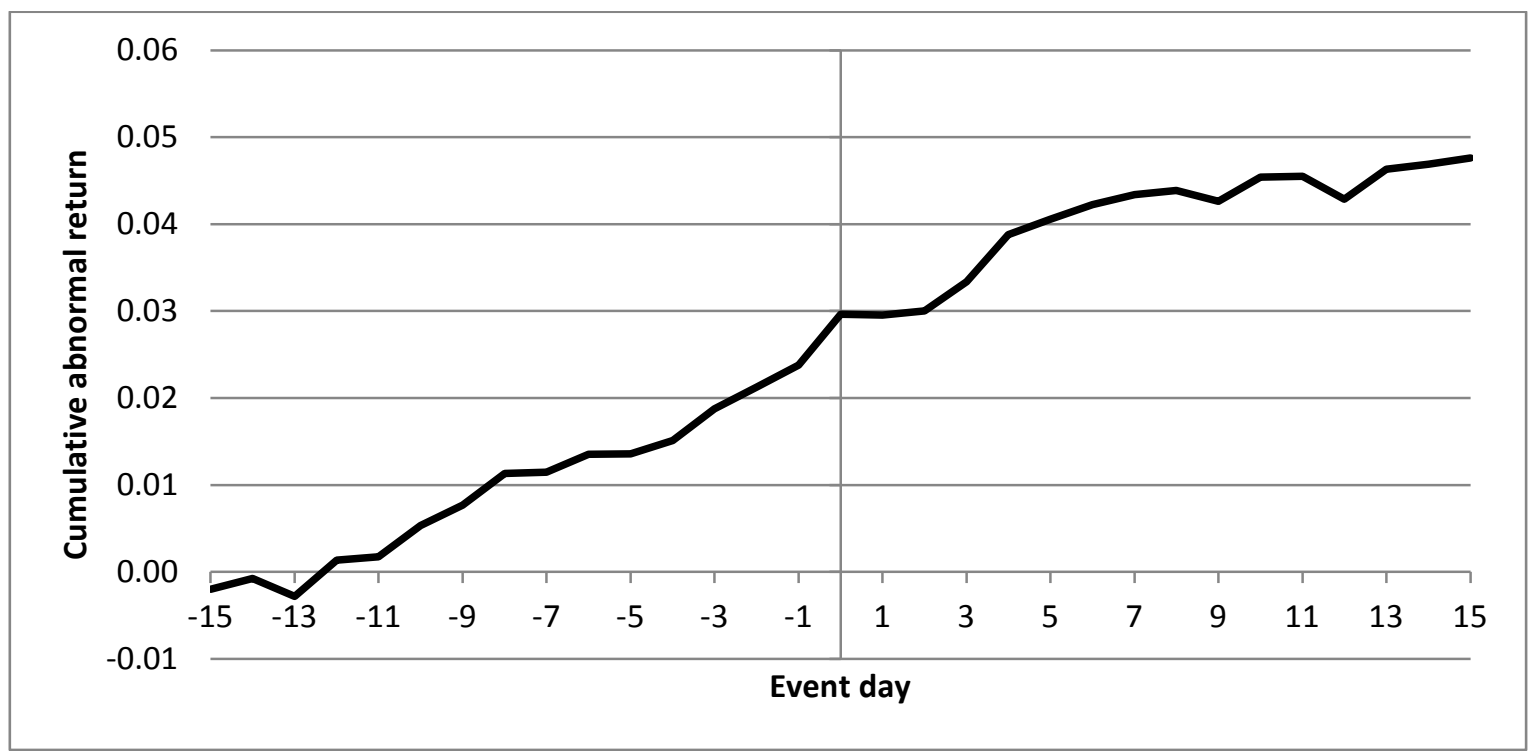

Figure 2

Daily abnormal turnover over event days -15 to 15

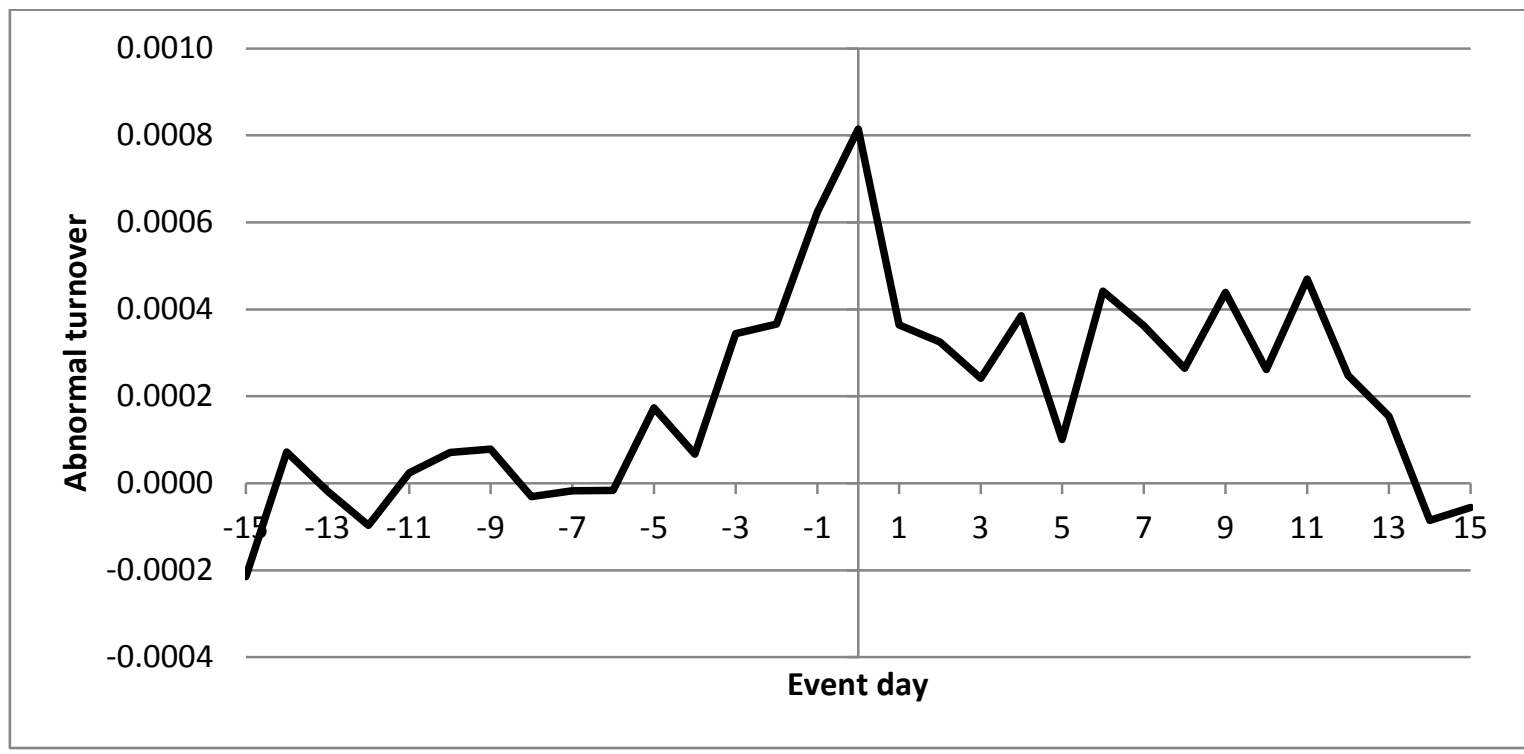




\section{Table 5}

Significance tests on abnormal returns and turnover

\begin{tabular}{|c|c|c|c|c|c|c|c|}
\hline \multirow[b]{2}{*}{ Event day } & \multicolumn{3}{|c|}{ Abnormal return } & \multicolumn{3}{|c|}{ Abnormal turnover } & \multirow[b]{2}{*}{$n$} \\
\hline & AR & $t$-stat & & ATURN & $t$-stat & & \\
\hline-15 & -0.0020 & -1.475 & & -0.0002 & -1.710 & + & 817 \\
\hline-14 & 0.0013 & 0.846 & & 0.0001 & 0.504 & & 817 \\
\hline-13 & -0.0017 & -1.130 & & 0.0000 & -0.135 & & 817 \\
\hline-12 & 0.0042 & 3.002 & $* *$ & -0.0001 & -0.820 & & 817 \\
\hline-11 & 0.0004 & 0.231 & & 0.0000 & 0.141 & & 817 \\
\hline-10 & 0.0036 & 2.178 & $*$ & 0.0001 & 0.438 & & 817 \\
\hline-9 & 0.0024 & 1.586 & & 0.0001 & 0.503 & & 817 \\
\hline-8 & 0.0037 & 2.638 & $* *$ & 0.0000 & -0.226 & & 817 \\
\hline-7 & 0.0001 & 0.088 & & 0.0000 & -0.119 & & 817 \\
\hline-6 & 0.0021 & 1.389 & & 0.0000 & -0.114 & & 817 \\
\hline-5 & 0.0000 & 0.022 & & 0.0002 & 1.179 & & 817 \\
\hline-4 & 0.0015 & 1.081 & & 0.0001 & 0.444 & & 817 \\
\hline-3 & 0.0036 & 2.419 & $*$ & 0.0003 & 1.601 & & 817 \\
\hline-2 & 0.0025 & 1.323 & & 0.0004 & 1.760 & + & 817 \\
\hline-1 & 0.0025 & 1.440 & & 0.0006 & 2.722 & $* *$ & 817 \\
\hline 0 & 0.0059 & 3.393 & $* * *$ & 0.0008 & 4.430 & $* * *$ & 817 \\
\hline 1 & -0.0001 & -0.090 & & 0.0004 & 2.619 & $* *$ & 817 \\
\hline 2 & 0.0005 & 0.306 & & 0.0003 & 2.248 & * & 817 \\
\hline 3 & 0.0034 & 2.053 & $*$ & 0.0002 & 1.499 & & 817 \\
\hline 4 & 0.0054 & 3.478 & $* * *$ & 0.0004 & 2.155 & * & 817 \\
\hline 5 & 0.0018 & 1.043 & & 0.0001 & 0.716 & & 817 \\
\hline 6 & 0.0017 & 1.057 & & 0.0004 & 2.776 & $* *$ & 817 \\
\hline 7 & 0.0011 & 0.552 & & 0.0004 & 2.310 & $*$ & 817 \\
\hline 8 & 0.0005 & 0.296 & & 0.0003 & 1.809 & + & 817 \\
\hline 9 & -0.0012 & -0.828 & & 0.0004 & 2.239 & $*$ & 817 \\
\hline 10 & 0.0028 & 1.713 & + & 0.0003 & 1.783 & + & 817 \\
\hline 11 & 0.0001 & 0.066 & & 0.0005 & 3.139 & $* *$ & 817 \\
\hline 12 & -0.0026 & -1.698 & & 0.0002 & 1.341 & & 817 \\
\hline 13 & 0.0034 & 1.978 & $*$ & 0.0002 & 1.081 & & 817 \\
\hline 14 & 0.0006 & 0.342 & & -0.0001 & -0.596 & & 817 \\
\hline 15 & 0.0007 & 0.488 & & -0.0001 & -0.350 & & 817 \\
\hline
\end{tabular}

Table 5 presents Student $t$-tests on daily $A R$ and $A T U R N$ to test for difference from 0 . AR is calculated per equation 1 and $A T U R N$ per equation 3. Two-tailed test of significance: $* * *=$ less than $.001, * *=$ less than $.01, *=$ less than .05 and $+=$ less than .10 . 


\section{Table 6}

Significance tests on CAR

\begin{tabular}{lccll}
\hline CAR window & CAR & t-stat & & n \\
\cline { 1 - 4 } Full sample & & & & \\
\cline { 1 - 4 }-15 to 15 & 0.048 & 5.888 & $* * *$ & 817 \\
-10 to 10 & 0.044 & 6.262 & $* * *$ & 817 \\
-5 to 5 & 0.027 & 5.640 & $* * *$ & 817 \\
-3 to 3 & 0.018 & 4.819 & $* * *$ & 817 \\
-1 to 1 & 0.008 & 3.145 & $* *$ & 817 \\
-15 to -3 & 0.019 & 4.103 & $* * *$ & 817 \\
-15 to -11 & 0.019 & 4.103 & $* * *$ & 817 \\
-10 to -6 & 0.012 & 3.685 & $* * *$ & 817 \\
-5 to -1 & 0.010 & 2.919 & $* *$ & 817 \\
3 to 15 & 0.018 & 3.226 & $* * *$ & 817 \\
1 to 5 & 0.011 & 3.133 & $* *$ & 817 \\
6 to 10 & 0.005 & 1.260 & & 817 \\
11 to 15 & 0.002 & 0.675 & & 817 \\
& & & & \\
\hline Restricted sample & & & & \\
\hline -15 to 200 & 0.003 & 0.066 & & 733
\end{tabular}

Table 6 presents Student $t$-tests on CAR to test for difference from 0 . CAR is calculated as per equations 1 and 2 . Two-tailed test of significance: $* * *=$ less than $.001, * *=$ less than $.01, *=$ less than .05 and $+=$ less than .10 . 


\section{Table 7}

The market reaction determinants of resource firm investor presentations

\begin{tabular}{|c|c|c|c|c|c|c|c|c|c|}
\hline \multirow[b]{2}{*}{ Variable } & \multicolumn{3}{|c|}{-15 to 15} & \multicolumn{3}{|c|}{$\mathbf{0}$} & \multicolumn{3}{|c|}{-15 to 200} \\
\hline & coeff. & $t$-stat & & coeff. & $t$-stat & & coeff. & $t$-stat & \\
\hline Intercept & 0.0079 & 0.113 & & 0.0128 & 0.641 & & -1.5105 & -5.301 & $* * *$ \\
\hline$D N D$ & -0.0110 & -0.614 & & -0.0107 & -2.455 & * & -0.0652 & -0.962 & \\
\hline AMEC & 0.0350 & 1.357 & & 0.0028 & 0.418 & & -0.1294 & -1.332 & \\
\hline$E M E$ & 0.0339 & 1.165 & & -0.0056 & -0.702 & & -0.0370 & -0.370 & \\
\hline$E O G$ & 0.1275 & 2.391 & $*$ & -0.0039 & -0.349 & & 0.2128 & 1.381 & \\
\hline$A D U$ & 0.0473 & 1.848 & + & -0.0004 & -0.063 & & 0.1068 & 1.040 & \\
\hline INT & 0.0484 & 3.037 & $* *$ & -0.0008 & -0.215 & & 0.1457 & 2.666 & $* *$ \\
\hline$A N N$ & -0.0158 & -1.034 & & 0.0083 & 2.418 & $*$ & -0.0821 & -1.579 & \\
\hline PREC & -0.0120 & -0.563 & & 0.0092 & 1.953 & + & 0.1396 & 1.550 & \\
\hline AUS & -0.0060 & -0.214 & & 0.0028 & 0.393 & & 0.1430 & 1.292 & \\
\hline PSDISC & 0.0045 & 2.306 & $*$ & -0.0002 & -0.653 & & 0.0035 & 0.429 & \\
\hline SIZE & -0.0019 & -0.466 & & 0.0007 & 0.614 & & 0.0927 & 6.005 & $* * *$ \\
\hline$M O M$ & -0.0002 & -2.861 & $* *$ & 0.0000 & -0.937 & & 0.0019 & 6.555 & $* * *$ \\
\hline TOP20 & 0.0004 & 1.108 & & -0.0004 & -2.675 & $* *$ & -0.0038 & -2.045 & * \\
\hline $\operatorname{Adj} . R^{2}$ & & $4.70 \%$ & & & $2.08 \%$ & & & $9.16 \%$ & \\
\hline$n$ & & 766 & & & 766 & & & 698 & \\
\hline
\end{tabular}

Table 7 presents regression results of the determinants of CAR calculated as per equations 1 and 2 over the indicated window centred on the firm presentation. DND is a binary variable equal to 1 for a Diggers and Dealers conference presentation; $A M E C$ is a binary variable equal to 1 for a Association of Mining \& Exploration Companies conference presentation; $E M E$ is a binary variable equal to 1 for an Excellence in Mining \& Exploration conference presentation; $E O G$ is a binary variable equal to 1 for a Excellence in Oil \& Gas conference presentation; $A D U$ is a binary variable equal to 1 for an Africa Downunder conference presentation; INT is a binary variable equal to 1 for the first presentation of firm $i$; ANN is a binary variable equal to 1 if the presentation by firm $i$ at time $t$ is announced to the market; $P R E C$ is the count of the words 'gold', 'silver', 'INT is a binary variable equal to 1 for the first presentation of firm $i$; ANN is a binary variable equal to 1 if the presentation by firm $i$ at time $t$ is announced to the market; PREC is the count of the words 'gold', 'silver', 'palladium', 'platinum' and 'precious' over mentions of all minerals in the annual report of firm $i$ in year $t$; AUS is the count of the word 'Australia' over mentions of all countries in the annual report of firm $i$ in year $t$;
PSDISC is the number of price-sensitive announcements issued by firm $i$ over the 15 days before and after event date $t$; SIZE is the natural logarithm of the market capitalization of firm $i$ as at the end of year $t$; MOM is $P S D I S C$ is the number of price-sensitive announcements issued by firm $i$ over the 15 days before and after event date $t$; SIZE is the natural logarithm of the market capitalization of firm $i$ as at the end of year $t$; $M O M$ is
the difference in S\&P GSCI spot price from the start of the presenting month to one year previously; TOP2O is the percentage of shares owned by the largest 20 shareholders, as reported in the annual report of firm $i$ in year $t$. Two-tailed test of significance: $* * *=$ less than $.001, * *=$ less than $.01, *=$ less than .05 and $+=$ less than .10 . 